\title{
ANALISIS PERBEDAAN EFEKTIVITAS ORGANISASI DITINJAU DARI KESESUAIAN, KEKUATAN, DAN TIPE BUDAYA
}

\author{
Retno Hartati ${ }^{1)}$ \\ Yunita Anggarini ${ }^{2}$ \\ ${ }^{1)}$ Sekolah Tinggi Ilmu Manajemen YKPN \\ e-mail: retnohartati@gmail.com \\ 2) Sekolah Tinggi Ilmu Manajemen YKPN \\ e-mail: unixe_nit@yahoo.com
}

\begin{abstract}
This study aims to identify and analyze how much influence the effectiveness of the organization's culture is viewed from the standpoint of suitability, strength and type of culture in Higher Education institutions. Respondents in this study were 150 structural officials from 40 universities in Indonesia, which is taken by using purposive sampling method. The analysis shows that the three cultural variables have different influence on the effectiveness. Variable types of culture (especially Adhocracy culture) is seen to have the highest impact on the effectiveness of variables (scores F: 52 577, sign 0.000), compared with the strength of the cultural variables (scores F: 37 197, sign 0.000), and the variables that influence the cultural appropriateness minimum (no effect) on the effectiveness (scores F: .620, .432 sign)
\end{abstract}

Keywords: organizational effectiveness, suitability, strength, type of culture, college

\section{PENDAHULUAN}

Efektivitas organisasi terbukti menjadi salah satu masalah yang paling ekstensif untuk diteliti semenjak perkembangan awal teori organisasi (Rojas, 2000). Di era tahun 1980-an, efektivitas organisasi mulai menjadi variabel yang menonjol dan beralih dari statusnya sebagai sebuah konstruk menjadi konsep (Henry, 2011). Beberapa artikel tentang pengujian efektivitas organisasi (Smith, 1998) menjelaskan tentang bagaimana pengukuran efektivitas organisasi dan indikator-indikator apa yang digunakan untuk mengujinya, sementara Sekaran dan Snodgrass (1986) memberikan kerangka pengujian efektivitas organisasi dan secara eksplisit menghubungkannya dengan faktor budaya. Artikel-artikel tersebut sepakat bahwa efektivitas organisasi tidak dapat dipisahkan dengan faktor lingkungan yang membentuk organisasi tersebut, terutama faktor budaya organisasi. Berbagai penelitian sejenis (Ashraf, Giti dan Abd Kadir, dkk., 2012) yang diterapkan di perguruan tinggi di Eropa dan Amerika Serikat seperti studi Anderson (2000), Smart (2003), Lejeune dan Vas (2009) juga menguji pengaruh budaya organisasi terhadap efektivitas organisasi. Hasil studi mereka menyimpulkan bahwa kinerja organisasi yang efektif dari perguruan tinggi jelas terikat dengan sifat budaya organisasinya. Bahkan Anderson (2000) menyarankan anggota perguruan tinggi untuk mencari tindakan spesifik untuk pembelajaran bagaimana memanfaatkan berbagai tipe budaya dalam rangka untuk mencapai performa organisasi yang maksimal.

Penelitian ini bermaksud untuk menganalisis seberapa besar pengaruh budaya terhadap efektifitas organisasi dipandang dari sudut pandang kesesuaian, kekuatan dan 
tipe budaya pada instansi Perguruan Tinggi, sehingga dirumuskan pertanyaan penelitian berikut (1) Apakah terdapat perbedaan pengaruh antara budaya yang sesuai (kongruen) dan tidak sesuai (tidak kongruen) terhadap efektivitas organisasi, (2) Apakah terdapat perbedaan pengaruh antara budaya yang kuat dan lemah terhadap efektivitas organisasi, dan (3) Apakah terdapat perbedaan pengaruh antara 4 (empat) tipe budaya yang berbeda terhadap efektivitas organisasi? Dalam penelitian ini pengertian "budaya organisasi" lebih difokuskan pada istilah kultur akademis yang pada intinya mengatur para pendidik agar mereka memahami bagaimana seharusnya bersikap terhadap profesinya, beradaptasi terhadap rekan kerja dan lingkungan kerjanya serta berlaku reaktif terhadap kebijakan pimpinannya, sehingga terbentuklah sebuah sistem nilai, kebiasaan (habits), citra akademis, ethos kerja yang terinternalisasikan dalam kehidupannya sehingga mendorong apresiasi dirinya terhadap peningkatan prestasi kerja. Peningkatan prestasi kerja tersebut dapat terbentuk oleh lingkungan organisasi itu sendiri maupun dikuatkan secara organisatoris oleh pimpinan akademis.

\section{KAJIAN TEORI}

\section{Teori Budaya Organisasi}

Semenjak ditemukannya konstruk budaya organisasional, berbagai konsep budaya organisasional telah muncul seperti Clark (1972), Schein (1981). Pandangan Schein menjadi kerangka konseptual yang banyak dipakai untuk menganalisis budaya organisasional (Hatch, 1993). Sampai dengan tahun 1978, analisis terhadap dimensi informal organisasi ini mulai bergeser pada budaya organisasional dengan munculnya studi Pettigrew (1979) yang berpendapat bahwa budaya organisasi terdiri dari sistem kognitif yang menjelaskan bagaimana orang berfikir, beralasan dan membuat keputusan. Budaya dibedakannya dalam beberapa level berbeda. Pada level terdalam budaya terdiri dari suatu set nilai, asumsi dan keyakinan yang kompleks yang mendefinisikan cara perusahaan menjalankan bisnisnya (Wallace, dkk, 1999).

Dalam perkembangannya banyak penulis yang mencoba mendefinisikan budaya organisasional. Ouchi (Schein, 1990) mendefinisikan budaya sebagai:

A set of symbols, ceremonies and myths that communicate the underlying values and beliefs of the organization to its employees.

Menurut teori Schein (1981, 1985, 1990, 1992), budaya organisasi didefinisikan sebagai:

"A pattern of shared basic assumptions that the group learned as it solved its problems of external adaptation and internal integration, that has worked well enough to be considered valid and, therefore, to be taught to new members as a correct way to perceive, think and feel in relation to those problems". (Schein 1992)

Schein berpendapat bahwa budaya organisasi adalah hasil pembelajaran dari pengalaman kelompok, yang sebagian besar tidak disadari (Schein 1992). Schein menganggap budaya sebagai fenomena tiga level: pada permukaan adalah artifact (artifak), kemudian values (nilai-nilai) dan pada bagian inti adalah asumsi dasar. Asumsi dasar mewakili keyakinankeyakinan yang bersifat taken for granted tentang kenyataan dan hakikat manusia. Nilai-nilai (values) adalah prinsip-prinsip sosial, filosofi, sasaran dan standar yang dipertimbangkan untuk mendapatkan nilai-nilai intrinsik. Artifak adalah hasil-hasil yang 
tampak nyata, berwujud dan dapat didengar melalui aktivitas yang berakar pada nilai dan asumsi. Menurut Schein asumsi dasar merupakan kunci untuk memahami (dan merubah) suatu budaya.

\section{Tipe-tipe Budaya Organisasi dan Pengukurannya}

Dalam perkembangan berikutnya dapat dilihat ada keterkaitan antara budaya dengan desain organisasi sesuai dengan desain budaya yang akan diterapkan. Budaya organisasi sangat penting dilakukan dalam sebuah organisasi. Hal ini bertujuan untuk menentukan budaya organisasi tersebut tergolong kuat atau lemah. Hal yang harus kita lakukan pertama kali dalam pengukuran budaya organisasi adalah menentukan jenis budaya pada organisasi tersebut dan selanjutnya, kita tentukan apakah budaya organisasi yang kita ukur termasuk dalam jenis budaya organisasi yang mana.

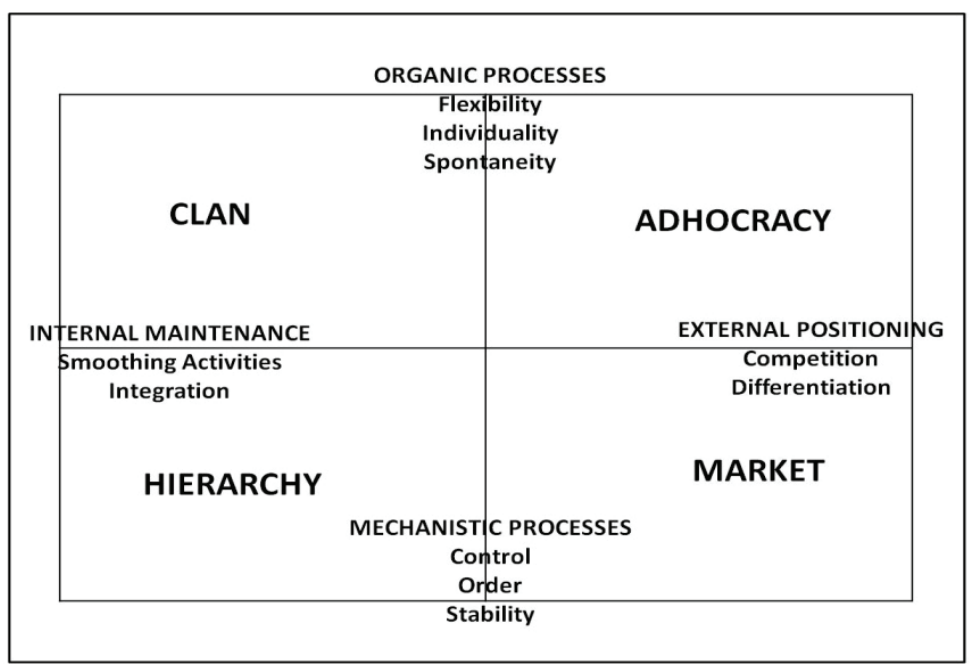

Sumber: Cameron \& Freeman, (1991)

Gambar 1. Empat Kuadran Tipe-Tipe Budaya Organisasi

Budaya organisasi yang kita miliki berbeda dengan budaya organisasi yang dimiliki oleh organisasi yang lain sehingga kita harus bisa mengenal jenis atau tipe budaya kita serta harus bisa mengetahui seberapa kuat budaya yang kita miliki. Untuk itu ada cara untuk mengukur budaya yang kita miliki. Menurut jenisnya budaya organisasi dibagi menjadi 4 jenis yaitu tipe clan, adhocracy, hierarchy, dan market. Keempat tipe budaya organisasi ini dibedakan berdasarkan cara kepemimpinan, fokus, indikator sukses, gaya organisasi, unsur yang menyatukan (merekatkan), serta pemimpin dalam organisasi tersebut. Dengan berdasar pemikiran bahwa budaya didefinisikan sebagai nilai, asumsi dan interpretasi dari anggota organisasi, dan karena dimensi-dimensi diorganisasikan oleh psychological level psikologi dan organisasional, maka berbasis kerangka Jungian, tipe-tipe budaya dikelompokkan kedalam 4 (empat) kuadran sebagaimana dapat dilihat pada Gambar 1 (Mitroff dan Kilmann, 1976). Adapun ilustrasi ciri-ciri setiap tipe budaya organisasi berdasar atribut dominan, tipe kepemimpinan, unsur perekat dan penekanan strategik sebagaimana dapat dilihat pada Tabel 1. 
Tabel 1. Model Kesesuaian Budaya Organisasi

\begin{tabular}{|c|c|c|}
\hline Type & Clan (A) & Adhocracy (B) \\
\hline Dominant Attribute & $\begin{array}{l}\text { Cohesiveness, participation, } \\
\text { teamwork, sense of family }\end{array}$ & $\begin{array}{l}\text { Creativity entrepreneurship, } \\
\text { adaptability, dynamism }\end{array}$ \\
\hline Leader style & Mentor, facilitator, parent-figure & Entrepreneur, innovator, risk taker \\
\hline Bonding & $\begin{array}{l}\text { Loyalty, tradition, interpersonal } \\
\text { cohesion }\end{array}$ & Entrepreneurship, flexibility, risk \\
\hline Strategic Emphasises & $\begin{array}{l}\text { Toward developing human } \\
\text { resources, commitment, morale }\end{array}$ & $\begin{array}{l}\text { Toward innovation, growth, new } \\
\text { resources }\end{array}$ \\
\hline Type & Hierarchy $(\mathrm{C})$ & Market (D) \\
\hline Dominant Attribute & $\begin{array}{l}\text { Order, Rules \& Regulation, } \\
\text { uniformity, efficiency }\end{array}$ & $\begin{array}{l}\text { Competitiveness, goal achievement, } \\
\text { environment exchange }\end{array}$ \\
\hline Leader style & $\begin{array}{l}\text { Coordinator, organizer, } \\
\text { administrator }\end{array}$ & $\begin{array}{l}\text { Decisive,production and } \\
\text { achievement-oriented }\end{array}$ \\
\hline Bonding & $\begin{array}{l}\text { Rules, policies and procedures, } \\
\text { clear expectetions }\end{array}$ & $\begin{array}{l}\text { Goal orientation, production, } \\
\text { competition }\end{array}$ \\
\hline Strategic Emphasises & $\begin{array}{l}\text { Toward stability, predictability, } \\
\text { smooth operations }\end{array}$ & Toward competitive advantage \\
\hline
\end{tabular}

Sumber: Cameron \& Freeman, (1991)

\section{Efektivitas Organisasi}

Menurut Kamus Besar Bahasa Indonesia (KKBI), kata efektif memiliki pengertian dapat membawa hasil atau berhasil guna. Sedangkan organisasi merupakan kesatuan (susunan) yang terdiri atas bagian-bagian (orang) untuk tujuan tertentu atau bias disebut juga kelompok kerja sama antara orang-orang yang diadakan untuk mencapai tujuan bersama. Pengertian lain dari kata efektifitas adalah suatu tingkat prestasi organisasi dalam mencapai tujuannya artinya kesejahteraan tujuan yang telah ditetapkan dapat dicapai. Robbins (1990) mendefinisikan efektivitas organisasi sebagai suatu tingkat dimana suatu organisasi dapat merealisasikan tujuannya.

Konsep ini terkait dengan isu-isu tentang kemampuan organisasi untuk mengakses dan menyerap sumber daya dan konsekuensinya pada pencapaian tujuan organisasi (Federman, 2006). Sebagaimana dinyatakan oleh Gigliotti (1987) bahwa sebuah unit kerja yang secara individual tidak efektif dalam hal kerja sama dengan keseluruhan organisasi akan mengalami kegagalan. Sementara Cameron (1978) menyatakan bahwa efektivitas organisasi merupakan kemampuan organisasi untuk memiliki akses ke sumber dayasumberdaya penting. Bahkan McCann (2004) mencatatnya sebagai kriteria kesuksesan organisasi untuk mencapai tujuannya melalui strategi inti.

Beberapa faktor kritis dalam mengukur keberhasilan suatu organisasi tergantung pada beberapa indikator/kriteria. Beberapa kriteria tersebut diantaranya tidak mudah untuk diukur secara kuantitatif, misalnya kepuasan, motivasi, dan moral. Kaplan dan Norton (1992, 1996) menemukan sebuah model yang memberikan alternatif untuk perbaikan dalam pengukuran efektitivitas organisasi atau kinerja organisasi yang dikenal dengan balanced scorecard yang menggunakan pengukuran internal maupun eksternal, kuantitatif maupun kualitatif, yang dibagi dalam empat perspektif, yaitu: 1) Keuangan, 2) Pelanggan, 3) Internal proses, dan 4) Inovasi. 


\section{Model-model Efektivitas Organisasi}

Berikut diuraikan tujuh model efektivitas organisasi antara lain (1) Model Tujuan (Goal Model), merupakan model universal (Bluedorn, 1980; Campbell, 1977; Price, 1972; Scott, 1977) menyatakan bahwa efektivitas organisasi harus dinilai dalam bentuk pencapaian hasil akhir bukan cara atau prosesnya, (2) Model Sumber Daya Sistem (System Resource Model) menekankan pada akuisisi sumber daya yang dibutuhkan sebagai kriteria penilaian efektifitas, (3) Model Multi Konstituen (Multiple Constituency Model) mengembangkan kriteria penilaian efektivitas organisasi atas dasar berbagai preferensi stakeholders yang berbeda terhadap kinerja organisasi, (4) Model Nilai Bersaing (The Competing Values Model) ini menekankan pada trade offs di antara berbagai kriteria dan perubahan yang terjadi dalam profil-profil organisasi, (5) Model Proses Internal (Internal Process Model), model ini didasarkan pada suatu rangkaian prinsip-prinsip normatif yang mengarahkan cara organisasi seharusnya berfungsi untuk mendorong pertumbuhan dan pengembangan manusia agar dapat mencapai potensi maksimum, (6) Model Legitimasi (Legitimated Model) beranggapan bahwa melakukan kerja yang benar jauh lebih penting dibanding melakukan kerja secara benar, dan (7) Model Ketidakefektifan (Ineffectiveness Model), model ini memusatkan pada faktor-faktor yang menghambat sukses kinerja organisasi, bukan faktor-faktor yang menyumbang keberhasilan. Suatu organisasi dinilai mencapai efektifitas tinggi bila bebas dari berbagai karakteristik ketidakefektifan.

Masing-masing model memiliki kelebihan dan kelemahan tersendiri. Ringkasan dari uraian di atas dapat dilihat pada Tabel 2.

Tabel 2. Model Efektivitas Organisasi

\begin{tabular}{|c|c|c|}
\hline Model & $\begin{array}{c}\text { Definisi } \\
\text { Sebuah organisasi adalah efektif bila } \\
\ldots \ldots \ldots \ldots \ldots \ldots\end{array}$ & $\begin{array}{c}\text { Kapan Berguna } \\
\text { Model paling terap bila ..... }\end{array}$ \\
\hline Tujuan & $\begin{array}{l}\text { mencapai tujuan-tujuan yang telah } \\
\text { ditetapkan }\end{array}$ & $\begin{array}{l}\text { tujuan-tujuan jelas, konseptual, berjangka } \\
\text { waktu, dan dapat diukur }\end{array}$ \\
\hline Sumber Daya Sistem & $\begin{array}{l}\text { mampu memperoleh sumber daya yang } \\
\text { dibutuhkan }\end{array}$ & ada kaitan jelas antara masukan dan kinerja \\
\hline Proses Internal & $\begin{array}{l}\text { tidak mempunyai hambatan internal dan } \\
\text { fungsi-fungsi internal berjalan lancar }\end{array}$ & $\begin{array}{l}\text { ada kaitan jelas antara berbagai proses } \\
\text { organisasional dan kinerja }\end{array}$ \\
\hline Multi Konstituen & $\begin{array}{l}\text { semua pihak terkait terpuaskan paling } \\
\text { tidak secara minimal }\end{array}$ & $\begin{array}{l}\text { pihak-pihak terkait mempunyai pengaruh } \\
\text { kuat terhadap organisasi, dan harus dipenuhi } \\
\text { permintaannya }\end{array}$ \\
\hline Nilai Bersaing & $\begin{array}{l}\text { memenuhi preferensi pihak-pihak terkait } \\
\text { dalam hal empat kuadran yang berbeda }\end{array}$ & $\begin{array}{l}\text { organisasi tidak jelas tentang kriterianya } \\
\text { sendiri, atau kriteria berubah setiap waktu }\end{array}$ \\
\hline Legitimasi & $\begin{array}{l}\text { kelangsungan hidupnya terjamin sebagai } \\
\text { hasil pelaksanaan kegiatan legitimate }\end{array}$ & $\begin{array}{l}\text { kelangsungan hidup atau penurunan dan } \\
\text { kematian organisasi adalah penting }\end{array}$ \\
\hline Ketidakefektifan & $\begin{array}{l}\text { tidak mempunyai kelemahan-kelemahan } \\
\text { atau sifat-sifat sumber ketidakefektifan }\end{array}$ & $\begin{array}{l}\text { kriteria efektifitas tidak jelas, atau berbagai } \\
\text { strategi perbaikan diperlukan }\end{array}$ \\
\hline
\end{tabular}

Sumber: Robbins, Stephen P. (1990), Bluedorn (1980), Campbell (1977); Price (1972); Scott (1977)

\section{Efektivitas Perguruan Tinggi Model Cameron dan Pengukurannya}

Efektivitas organisasi merupakan topik yang diteliti secara luas (Rojas, 2000) dan Karagoz dan $\mathrm{Oz}$ (2008), penelitian tentang efektivitas organisasi dimulai pada tahun 1930-an, yang kemudian diperluas oleh banyak teori dan pendekatan di tahun 1970an dan seterusnya. Berbagai indikator dengan pandangan yang sama telah diadopsi untuk mengevaluasi keefektifan organisasi yang diterapkan diberbagai perguruan tinggi 
(lihat Tabel 1 tentang penelitian terdahulu). Dalam studi yang lain, penerapan model Cameron (1978) ini dirancang untuk mengevaluasi efektivitas perguruan tinggi. Berbagai literatur menyebutkan bahwa model ini menjadi acuan banyak peneliti di teori organisasi (Gigliotti, 1987; Hertelendy, 2010; Kwan \& Walker, 2003; Lejeune \& Vas, 2009, Smart, 2003; Vinitwatanakhun, 1998). Ashraf, Giti dan Abd Kadir, dkk. (2012) menyatakan bahwa hasil pengkajian model ini memberikan beberapa bukti tentang kesesuaian dalam efektivitas organisasi penilaian di area pendidikan tinggi.

Model yang diusulkan Cameron (1978) adalah 9 (sembilan) dimensi dari efektivitas organisasi dalam 57 item kuesioner. Pemilihan dimensi Cameron tersebut didasarkan pada studi yang cermat terhadap kriteria, institusi dan konstituen, serta melalui analisis yang mendalam (Siddiqui, 2010). Validitas dan keandalan kuesioner efektivitas organisasi Cameron telah dilaporkan oleh beberapa peneliti, seperti Anderson (2000) melaporkan Cronbach alpha 0,66-0,85, Smart (2003) menemukan Koefisien alpha 0,66-0,85, dan Lejeune \& Vas (2009) dihitung Cronbach alpha 0,65-0,87 untuk masing-masing dari sembilan dimensi. Selain itu, Kwan dan Walker (2003) melaporkan alpha keandalan 0,760,87 untuk tujuh dimensi instrumen efektivitas organisasi di lembaga pendidikan tinggi di Hong Kong. Dengan demikian pemilihan model Cameron ini merupakan alat yang tepat untuk mengukur efektivitas organisasi khususnya di institusi perguruan tinggi. Berikut ini sembilan dimensi tersebut (1) Kepuasan Pendidikan Mahasiswa (Student educational satisfaction), (2) Pengembangan akademik mahasiswa (Student academic development), (3) Pengembangan karir mahasiswa (Student career development), (4) Pengembangan pribadi mahasiswa (Student personal development), (5) Kepuasan kerja karyawan (administrasi maupun fakultas) (Faculty and administrator employment satisfaction), (6) Kualitas dan Pengembangan Profesional fakultas (Professional development and quality of the faculty, (7) Keterbukaan Sistem dan interaksi masyarakat (System openness and community interaction), (8) Kemampuan organisasi untuk memperoleh sumber daya (Ability to acquire resources), dan (9) Kesehatan organisasi (Organizational health).

\section{Penelitian Terdahulu}

Pengaruh Budaya Organisasi terhadap Efektivitas Organisasi. Berikut ini disajikan beberapa studi internasional yang secara luas mengkaji keterkaitan antara budaya organisasi dengan efektivitas organisasi yang menerapkan model Cameron. Sebagai contoh Anderson (2000) melakukan studi Community Colleges di Tennessee Amerika Serikat, di mana peneliti memanfaatkan 16 item budaya organisasi dari instrumen Cameron dan 36 item kuesioner efektivitas organisasi model Cameron. Hasil studi menunjukkan bahwa empat jenis budaya organisasi (clan, adhocracy, hierarchy dan market) berhubungan secara signifikan dengan efektivitas organisasi di Community Colleges Tennessee tersebut, dengan tingkat signifikansi yang kuat $(\mathrm{p}<.001)$ dan positif. Selain itu, terungkap bahwa instrumen Cameron bekerja sebagai alat diagnostik yang sangat bermanfaat bagi perguruan tinggi.

Dalam studi lain di 14 perguruan tinggi di beberapa negara bagian USA dengan berdasarkan model nilai-nilai kompetitif Cameron dan instrumen efektivitas organisasi Cameron oleh Smart (2003) menyimpulkan bahwa kinerja organisasi yang efektif dari perguruan tinggi jelas terikat dengan sifat budaya organisasinya. Peneliti mengajukan saran bahwa budaya kampus yang paling efektif adalah budaya yang mencerminkan keseimbangan yang sehat dari keempat jenis budaya (clan, adhocracy, hierarchy, dan 
market) dibanding hanya berfokus pada salah satu atau dua dari jenis budaya tersebut. Selain itu ditemukan pula tentang pentingnya peran pemimpin institusi dalam pengelolaan dan perubahan budaya.

Dalam survei Lejeune dan Vas (2009) di Eropa menilai efek yang dirasakan dari proses akreditasi pada budaya dan efektivitas organisasi. Sampel yang dijadikan sebagai obyek penelitian meliputi 31 dekan dan pimpinan bagian sistem penjaminan mutu di beberapa perguruan tinggi Eropa yang telah terakreditasi. Hasil studi menunjukkan bahwa terdapat efek positif pada beberapa aspek efektivitas. Secara khusus hasil penelitian menunjukkan bahwa terdapat dua tipe budaya yang terkait erat dengan efektivitas yakni, market dan adhocracy dan bahwa perubahan budaya yang diciptakan oleh akreditasi memiliki efek positif terhadap kinerja.

Pengukuran Efektivitas Organisasi. Berdasarkan kajian pada hasil penelitian sebelumnya yang menerapkan pengukuran efektivitas organisasi dengan Model Cameron diperoleh hasil sebagaimana dipaparkan pada Tabel 3.

Tabel 3. Penelitian Terdahulu tentang Pengukuran Efektivitas Organisasi

\begin{tabular}{|c|c|c|c|c|}
\hline No & Peneliti & & Kriteria Efektivitas & Hasil Penelitian \\
\hline 1. & $\begin{array}{l}\text { Antia dan } \\
\text { Cuthbert } \\
(1976)\end{array}$ & $\begin{array}{l}\text { 1) } \\
\text { 2) } \\
\text { 3) } \\
\text { 4) } \\
\text { 5) } \\
\text { 6) } \\
\text { 7) } \\
\text { 8) } \\
\text { 9) }\end{array}$ & $\begin{array}{l}\text { social tone } \\
\text { cost effectiveness } \\
\text { course development } \\
\text { corporate reputation } \\
\text { investment in human capital } \\
\text { physical facilities development } \\
\text { student relations } \\
\text { the quality of employee relations } \\
\text { public responsibility }\end{array}$ & $\begin{array}{l}\text { Parameter-parameter tersebut berkaitan erat } \\
\text { satu sama lain, dimana jika salah satu parameter } \\
\text { negatif (tidak memberi prestasi), maka sangat } \\
\text { mungkin bahwa faktor negatif tersebut akan } \\
\text { mempengaruhi fungsi secara total. }\end{array}$ \\
\hline 2. & $\begin{array}{l}\text { Kleeman } \\
\text { dan } \\
\text { Richardson } \\
(1985)\end{array}$ & $\begin{array}{l}\text { 1) } \\
\text { 2) } \\
\text { 3) } \\
\text { 4) } \\
\text { 5) } \\
\text { 6) } \\
\text { 7) } \\
\text { 8) } \\
\text { 9) } \\
\text { 10) }\end{array}$ & $\begin{array}{l}\text { programs and services for students } \\
\text { attention to women and minorities } \\
\text { quality of teaching and research } \\
\text { publication of knowledge and } \\
\text { research } \\
\text { workshops and counseling to } \\
\text { broaden access } \\
\text { sports } \\
\text { focus on cultural activities } \\
\text { programs for graduates } \\
\text { leasing facilities } \\
\text { enhancement of standards }\end{array}$ & $\begin{array}{l}\text { Kesimpulan: mahasiswa meyakini bahwa } \\
\text { pengertian sebagai peningkatan layanan dan } \\
\text { program untuk mahasiswa, efisiensi pendidikan } \\
\text { dan penelitian dan penawaran program untuk } \\
\text { para lulusan yang berkualitas tinggi merupakan } \\
\text { hal serius yang harus dikembangkan di } \\
\text { universitas }\end{array}$ \\
\hline 3. & $\begin{array}{l}\text { Pounder } \\
\text { (1999) }\end{array}$ & $\begin{array}{l}\text { 1) } \\
\text { 2) } \\
\text { 3) } \\
\text { 4) } \\
\text { 5) } \\
\text { 6) } \\
\text { 7) } \\
\text { 8) } \\
\text { 9) }\end{array}$ & $\begin{array}{l}\text { productivity-efficiency } \\
\text { quality } \\
\text { Cohesion } \\
\text { adaptability-readiness } \\
\text { information management- } \\
\text { communication } \\
\text { growth } \\
\text { planning-goal setting } \\
\text { human resource development } \\
\text { stability-control }\end{array}$ & $\begin{array}{l}\text { Hasil penelitian menunjukkan perbaikan dalam } \\
\text { skala untuk peringkat valid dan reliabel/ handal } \\
\text { pada dimensi seperti planning-goal setting, } \\
\text { information management communi-cation, } \\
\text { cohesion dan productivity-efficiency. Peneliti } \\
\text { meyakini bahwakeempat dimensi sisanya tersebut } \\
\text { merupakan aspek utama dari model efektivitas } \\
\text { organisasi pada pendidikan tinggi di Hong Kong. } \\
\text { Hal ini karena adanya tingkat partisipasi yang } \\
\text { tinggi dan kemajuan yang baik dalam prosedur } \\
\text { pengembangan skala. }\end{array}$ \\
\hline
\end{tabular}

Sumber: Antia dan Cuthbert (1976), Kleeman dan Richardson (1985), Pounder (1999), dan Ashraf, Giti dan Abd Kadir, Suhaida bte, (2012) 
Berdasarkan hasil-hasil penelitian diatas menunjukkan bahwa instrumen yang akan digunakan dalam penelitian ini yakni model Cameron telah divalidasi oleh semua studi empiris tersebut dan dengan demikian merupakan alat yang efisien untuk penilaian efektivitas organisasi. Dengan berdasar pada uraian di atas, maka diajukan 3 (tiga) hipotesis penelitian berikut: (1) Hipotesis 1: Tidak ada perbedaan pengaruh antara budaya yang sesuai (kongruen) dan tidak sesuai (tidak kongruen) terhadap efektivitas organisasi, (2) Hipotesis 2: Tidak ada perbedaan pengaruh antara budaya yang kuat dan lemah terhadap efektivitas organisasi, dan (3) Hipotesis 3: Tidak ada perbedaan pengaruh antara 4 (empat) tipe budaya yang berbeda terhadap efektivitas organisasi.

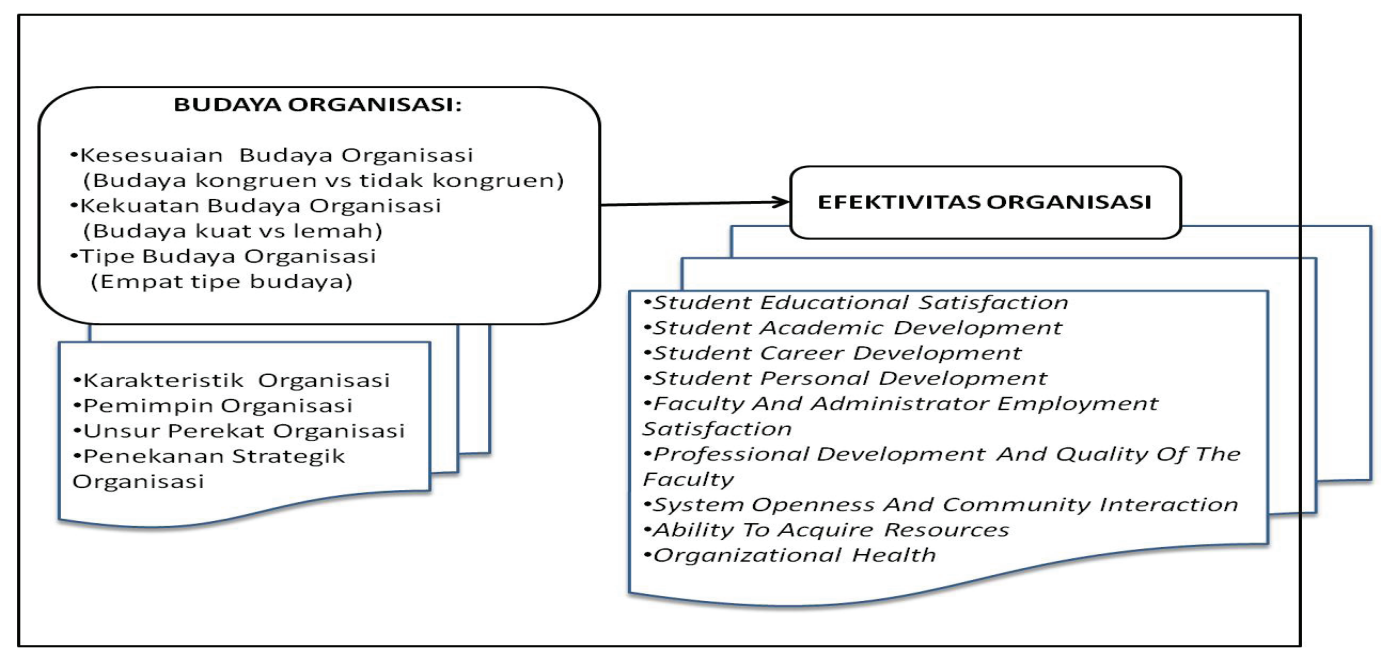

Gambar 2. Model Penelitian

\section{METODE PENELITIAN}

\section{Populasi dan Sampel Penelitian}

Penelitian ini akan dilaksanakan di Indonesia. Populasi dalam penelitian ini adalah pejabat struktural dari Perguruan Tinggi di Indonesia. Pemilihan responden tersebut karena diharapkan mereka sudah memiliki pengetahuan tentang penelitian ini dan dapat membantu memberikan data yang dapat dipertanggungjawabkan.

Karena keterbatasan waktu dan biaya, penelitian ini hanya akan mengambil sejumlah sampel dari seluruh anggota populasi yang ada. Sampel penelitian meliputi sejumlah elemen (responden) yang lebih besar dari persyaratan minimal sebanyak 30 elemen/responden. Menurut Guilford (1987), dimana semakin besar sampel (makin besar $\mathrm{n}=$ banyaknya elemen sampel) akan memberikan hasil yang lebih akurat. Dalam penelitian ini sampel dipilih 200 responden dari 40 Perguruan Tinggi di Indonesia. Metode pengambilan sampel menggunakan non-probability Sampling secara purposive sampling. Kuesioner dibagikan kepada 200 responden dari 40 Perguruan Tinggi. Jumlah kuesioner yang kembali adalah sebanyak 175 kuesioner. Sebanyak 150 responden yang memenuhi syarat untuk dianalisa, 25 kuesioner tidak dapat diproses lebih lanjut karena alasan teknis, seperti isian yang tidak lengkap, isian kabur dan jawaban tidak memenuhi kriteria analisis. 


\section{Teknik Pengumpulan Data}

Sumber data dalam penelitian ini adalah data primer. Data primer diperoleh langsung dari pejabat struktural Perguruan Tinggi di Indonesia. Metode pengumpulan data dalam penelitian ini menggunakan kuesioner, yaitu pengumpulan data yang dilakukan dengan cara memberikan seperangkat pernyataan atau pertanyaan tertulis kepada responden untuk dijawabnya. Dalam mengukur budaya organisasi dapat digunakan berbagai metode, seperti kuesioner, karena pada kenyataannya tidak ada alat konkret untuk melakukan pengukuran budaya organisasi (Cameron \& Freeman, 1991). Berbasis 4 (empat) indikator kriteria digunakan untuk mengukur budaya organisasi. kuesioner untuk setiap tipe dan kriteria budaya organisasi dapat dilihat pada Tabel 4.

Tabel 4. Dimensi, Tipe, dan Kuesioner Budaya Organisasi

\begin{tabular}{|c|c|c|c|}
\hline No & Dimensi & Tipe & Pertanyaan \\
\hline \multirow[t]{4}{*}{1.} & $\begin{array}{l}\text { Karakteristik } \\
\text { Organisasi }\end{array}$ & Clan & $\begin{array}{l}\text { Bagi saya kantor merupakan ruang pribadi (personal). Serasa dalam } \\
\text { keluarga besar. Orang2 menyukai berbagi tentang dirinya }\end{array}$ \\
\hline & & Adhocracy & $\begin{array}{l}\text { Menurut saya Institusi saya lebih mirip sebuah tempat yang dinamis dan } \\
\text { bernuansa enterpreneurship }\end{array}$ \\
\hline & & Hierarchy & $\begin{array}{l}\text { Menurut saya kantor ini merupakan tempat yang formal dan terstruktur. } \\
\text { Secara umum disini Prosedur yang birokratis mengatur apa yang orang- } \\
\text { orang lakukan }\end{array}$ \\
\hline & & Market & $\begin{array}{l}\text { Bagi saya institusi ini lebih ke orientasi produksi, dimana berfokus pada } \\
\text { pencapaian penyelesain kerja. Orang-orang kurang terlibat secara personal } \\
\text { (pribadi) }\end{array}$ \\
\hline \multirow[t]{4}{*}{2.} & $\begin{array}{l}\text { Pemimpin } \\
\text { Organisasi }\end{array}$ & Clan & $\begin{array}{l}\text { Gambaran pemimpin disini adalah seorang mentor, seorang yang bijak } \\
\text { dan figur ayah/keibuan }\end{array}$ \\
\hline & & Adhocracy & $\begin{array}{l}\text { Seorang entrepreneur, inovator dan berani resiko lebih menggambarkan } \\
\text { karakteristik pemimpin institusi disini }\end{array}$ \\
\hline & & Hierarchy & $\begin{array}{l}\text { Gambaran pemimpin disini adalah sebagai seorang koordinator, pengelola } \\
\text { dan administrator }\end{array}$ \\
\hline & & Market & $\begin{array}{l}\text { Produser, teknisian dan pekerja keras lebih menggambarkan karakteristik } \\
\text { pemimpin institusi disini }\end{array}$ \\
\hline \multirow[t]{4}{*}{3.} & $\begin{array}{l}\text { Perekat } \\
\text { Organisasi }\end{array}$ & Clan & $\begin{array}{l}\text { Perekat yang menjadi pegangan bersama dalam institusi ini adalah } \\
\text { loyalitas dan tradisi. Komitmen menjadi hal tertinggi disini }\end{array}$ \\
\hline & & Adhocracy & $\begin{array}{l}\text { Perekat yang menjadi pegangan bersama dalam institusi ini adalah } \\
\text { komitmen pada inovasi dan pengembangan. Hal itu yang menjadi } \\
\text { penekanan utama }\end{array}$ \\
\hline & & Hierarchy & $\begin{array}{l}\text { Perekat yang menjadi pegangan bersama dalam institusi ini adalah aturan } \\
\text { formal dan kebijakan. Mempertahankan institusi yang berjalan lancar } \\
\text { merupakan hal penting disini }\end{array}$ \\
\hline & & Market & $\begin{array}{l}\text { Perekat yang menjadi pegangan bersama dalam institusi ini adalah } \\
\text { pencapaian tugas dan tujuan }\end{array}$ \\
\hline \multirow[t]{4}{*}{4.} & $\begin{array}{l}\text { Penekanan } \\
\text { Organisasi }\end{array}$ & Clan & $\begin{array}{l}\text { Institusi disini lebih menekankan pada SDM. Moral dan kohesi (keeratan } \\
\text { hubungan) menjadi faktor penting (A) }\end{array}$ \\
\hline & & Adhocracy & $\begin{array}{l}\text { Institusi disini lebih menekankan pada pertumbuhan dan pemerolehan SD } \\
\text { yang baru. Kesiapan menghadapi tantangan baru menjadi faktor penting }\end{array}$ \\
\hline & & Hierarchy & $\begin{array}{l}\text { Institusi disini lebih menekankan pada stabilitas dan sifat permanen. } \\
\text { Efisien, dan operasi yang lancar menjadi faktor penting }\end{array}$ \\
\hline & & Market & $\begin{array}{l}\text { Institusi disini lebih menekankan pencapaian dan tindakan bersaing. } \\
\text { Pengukuran tujuan menjadi faktor penting }\end{array}$ \\
\hline
\end{tabular}

Sumber: Cameron \& Freeman, (1991) 


\section{Analisis Data}

Analysis of Variance (ANOVA) digunakan dalam penelitian ini. Analisis data diawali pada variabel budaya organisasi dengan pengujian terhadap tingkat kesesuaian, kekuatan, dan tipe budaya organisasi. Dengan menggunakan 4 (empat) kriteria penilaian mencakup karakteristik organisasi, gaya kepemimpinan, unsur perekat dan penekanan strategik dalam organisasi, responden diminta menetapkan skor yang paling sesuai dengan kondisi organisasinya. Nilai skor berjarak antara 0-100 poin, dimana semakin tinggi skor di dalam atribut yang dinilai, semakin kuat/ dominan atribut budaya tersebut. Analisis dilakukan dengan menghitung rata-rata masing-masing atribut.

Pengujian efektivitas organisasi diperoleh melalui pendapat responden dalam skala likert yang berada dalam rentang nilai 1 sampai dengan 5 pada masing-masing skala, dimana nilai 1 menunjukkan nilai paling rendah dan nilai 5 adalah nilai tertinggi. Sifat psikometrik dari 9 (sembilan) dimensi efektivitas diselidiki untuk menentukan reliabilitas dan validitas mereka. Skor efektivitas organisasi dihitung dengan rata-rata nilai semua responden di setiap Perguruan Tinggi pada masing-masing sembilan dimensi.

Data-data tersebut kemudian dianalisis dengan Analysis of Variance (ANOVA), yakni satu metode statistik yang digunakan untuk menguji signifikansi perbedaan dari 2 (dua) rata-rata populasi atau lebih (Munir, Sahibul, 2008). Asumsi-asumsi yang melandasi analisis ini adalah (1) Populasi yang akan diuji berdistribusi normal, (2) Varians dari populasi-populasi tersebut adalah sama, dan (3) Sampel tidak berhubungan satu dengan yang lain. Oleh karena itu sebelumnya dilakukan uji asumsi klasik meliputi (1) uji normalitas, (2) uji heterokedastisitas, dan (3) uji autokorelasi data.

\section{HASIL DAN PEMBAHASAN}

Analisis data berfokus pada identifikasi kepemilikan institusi atas kongruensi budaya, kekuatan budaya dan tipe budaya yang ditampilkan organisasi. Pada penelitian ini digunakan studi yang bersifat deskriptif, yang memberikan penjelasan dan gambaran tentang analisis ketiga faktor budaya tersebut terhadap efektivitas organisasi. Analisis dilakukan dengan mengukur rata-rata poin yang diberikan oleh responden pada setiap atribut dari masing-masing institusi.

Tabel 5. Klasifikasi Kekuatan Budaya

\begin{tabular}{clcc}
\hline No & Kekuatan Budaya & Jumlah Responden & Persentase \\
\hline 1. & Sangat Lemah & 0 & - \\
2. & Lemah & 0 & - \\
3. & Sedang & 5 & $3,3 \%$ \\
4. & Kuat & 96 & $64,0 \%$ \\
5. & Sangat Kuat & 49 & $32,7 \%$ \\
\hline & Total & 150 & $100,0 \%$ \\
\hline
\end{tabular}

Sumber : Olah Data penelitian 2014

Tabel 5 menunjukkan bahwa jumlah responden yang memberikan tanggapan kuesioner atas pertanyaan mengenai kekuatan budaya institusinya adalah sebanyak 49 orang (49\%) adalah budaya yang Sangat Kuat, sebanyak 96 orang (64\%) adalah Kuat, dan yang Sedang adalah sebanyak 5 orang (3,3\%). Pengelompokan tersebut didasarkan 
pada peringkat distribusi normal (skor $<20=$ Sangat Lemah, 20-40= Lemah, $40-60=$ Sedang, $60-80=$ Kuat dan $80-100=$ Sangat Kuat).

Tabel 6. Klasifikasi Kesesuaian (Congruency) Budaya

\begin{tabular}{clcc}
\hline No & Kesesuaian Budaya & Jumlah Responden & Persentase \\
\hline 1. & Kongruen & 121 & $80,7 \%$ \\
2. & Cukup & 24 & $16,0 \%$ \\
3. & Tidak Kongruen & 5 & $3,3 \%$ \\
\hline \multicolumn{5}{r}{ Total } & 150 & \\
\hline
\end{tabular}

Sumber : Olah Data penelitian 2014

Tabel 6 menunjukkan bahwa jumlah responden yang memberikan tanggapan kuesioner atas pertanyaan mengenai kesesuaian budaya institusinya adalah sebanyak 121 orang (80,7\%) menyatakan adanya kesesuaian budaya (kongruen), sebanyak 24 orang (16\%) adalah cukup, dan sebanyak 5 orang $(3,3 \%)$ adalah tidak sesuai/tidak kongruen.

Tabel 7. Klasifikasi Tipe Budaya

\begin{tabular}{|c|c|c|c|}
\hline No & Tipe Budaya & Jumlah Responden & Persentase \\
\hline 1. & Clan & 82 & $54,7 \%$ \\
\hline 2. & Adhocracy & 20 & $13,3 \%$ \\
\hline 3. & Hierarchy & 40 & $26,7 \%$ \\
\hline 4. & Market & 8 & $5,3 \%$ \\
\hline
\end{tabular}

Sumber : Olah Data penelitian 2014

Tabel 7 menunjukkan bahwa jumlah responden yang memberikan tanggapan kuesioner atas pertanyaan mengenai tipe budaya institusinya adalah sebanyak 82 orang (54,7\%) adalah tipe budaya Clan, sebanyak 20 orang (13,3\%) adalah Adhocracy, sebanyak 40 orang $(26,7 \%)$ adalah Hierarchy, dan tipe budaya Market sebanyak 8 orang $(5,3 \%)$. Sedangkan tabel 8 mengklasifikasikan kelompok yang efektivitas tinggi (efektif) sebanyak 79 orang $(52,7 \%)$ dan yang tidak efektif sebanyak 71 orang $(47,3 \%)$.

Tabel 8. Klasifikasi Efektivitas

\begin{tabular}{clcc}
\hline No & Keterangan & Jumlah Responden & Persentase \\
\hline 1. & Efektif & 79 & $52,7 \%$ \\
2. & Tidak Efektif & 71 & $47,3 \%$ \\
\hline
\end{tabular}

Sumber : Olah Data penelitian 2014

\section{Uji Validitas dan Reliabilitas Penelitian}

Untuk mendapatkan hasil yang bisa dipertanggungjawabkan, maka isian kuesioner responden perlu diuji sampai sejauh mana kuesioner yang digunakan benar-benar mengukur apa yang ingin diukur (validitas). Hasil pengujian validitas ini adalah sebagai berikut: 
Tabel 9. Hasil Uji Validitas Efektivitas

\begin{tabular}{lcc}
\hline \multicolumn{1}{c}{ Dimensi Pertanyaan } & Korelasi & $\begin{array}{c}\text { Kriteria Valid } \\
\text { Tingkat sig }<5 \%\end{array}$ \\
\hline $\begin{array}{l}\text { Kepuasan pendidikan mahasiswa (Student } \\
\text { educational satisfaction/SES) }\end{array}$ & 0,528 & Valid \\
$\begin{array}{l}\text { Pengembangan akademik mahasiswa (Student } \\
\text { academic development/SAD) }\end{array}$ & 0,530 & Valid \\
$\begin{array}{l}\text { Pengembangan karir mahasiswa (Student career } \\
\text { development/SCD) }\end{array}$ & 0,560 & Valid \\
$\begin{array}{l}\text { Pengembangan pribadi mahasiswa (Student } \\
\text { personal development/SPD) }\end{array}$ & 0,575 & Valid \\
$\begin{array}{l}\text { Kepuasan kerja karyawan (Faculty and } \\
\text { administrator employment satisfaction/FAES). }\end{array}$ & 0,589 & Valid \\
$\begin{array}{l}\text { Kualitas dan pengembangan profesional fakultas } \\
\text { (Professional development and quality of the }\end{array}$ & 0,646 & Valid \\
$\begin{array}{l}\text { faculty/PI) } \\
\text { Keterbukaan sistem dan interaksi masyarakat } \\
\text { (System openness and community interaction/ }\end{array}$ & 0,628 & Valid \\
$\begin{array}{l}\text { SOCI) } \\
\text { Kemampuan organisasi untuk memperoleh } \\
\text { sumber daya (Ability to acquire resources/AAR) }\end{array}$ & 0,578 & Valid \\
Kesehatan organisasi (Organizational health/ \\
OH)
\end{tabular}

Sumber: Olah Data penelitian 2014

Tabel 10. Hasil Uji Validitas Budaya

\begin{tabular}{lcc}
\hline \multicolumn{1}{c}{ Dimensi Pertanyaan } & Korelasi & $\begin{array}{c}\text { Kriteria Valid } \\
\text { Tingkat sig }<5 \%\end{array}$ \\
\hline Tipe Budaya Clan & 0,910 & Valid \\
Tipe Budaya Adhocracy & 0,882 & Valid \\
Tipe Budaya Hierarchy & 0,858 & Valid \\
Tipe Budaya Market & 0,867 & Valid \\
Kekuatan Budaya & 0,785 & Valid \\
Kesesuaian Budaya (congruence) & 0,965 & Valid \\
\hline
\end{tabular}

Sumber : Olah Data penelitian 2014

Berdasarkan hasil uji validitas menunjukkan bahwa butir-butir kuesioner dalam penelitian ini adalah valid hal ini ditunjukkan dengan nilai $r$ hitung (rxy) lebih kecil dari $r$ tabel dengan signifikansi lebih kecil dari 0,05 , artinya seluruh butir pertanyaan dapat digunakan sebagai instrumen penelitian

\section{Uji Reliabilitas}

Uji reliabilitas adalah pengujian mengenai kekonsistenan jawaban responden. Hasil pengujian reliabilitas variabel penelitian disajikan Tabel 11. 
Tabel 11. Hasil Uji Reliabilitas Efektivitas dan Budaya

\begin{tabular}{lcll} 
& Variabel & $\mathrm{R}$ & $\begin{array}{l}\text { Kriteria } \\
\text { reliable }\end{array}$ \\
\hline Budaya & 0,861 & Reliabel \\
Efektivitas & 0,852 & Reliabel \\
\hline
\end{tabular}

Sumber : Analisis Data Data penelitian 2014

Berdasarkan hasil pengujian reliabilitas terhadap seluruh item pertanyaan diperoleh hasil skor $>0,6$ sehingga dapat disimpulkan bahwa seluruh item pertanyaan penelitian ini telah memenuhi syarat reliabilitas atau dengan kata lain bahwa kuesioner ini reliabel sebagai instrumen penelitian.

\section{ANALISIS ANOVA}

Untuk menjawab permasalahan yang ada, maka peneliti menggunakan Analisis ANOVA, yakni melakukan uji beda (ANOVA) efektivitas masing-masing perguruan tinggi untuk mengetahui pengaruh dari ketiga faktor budaya (kongruensi, kekuatan dan tipe budaya) terhadap efektivitas organisasi tersebut.

Tabel 12. Hasil ANOVA

Uji beda tipe budaya - efektivitas

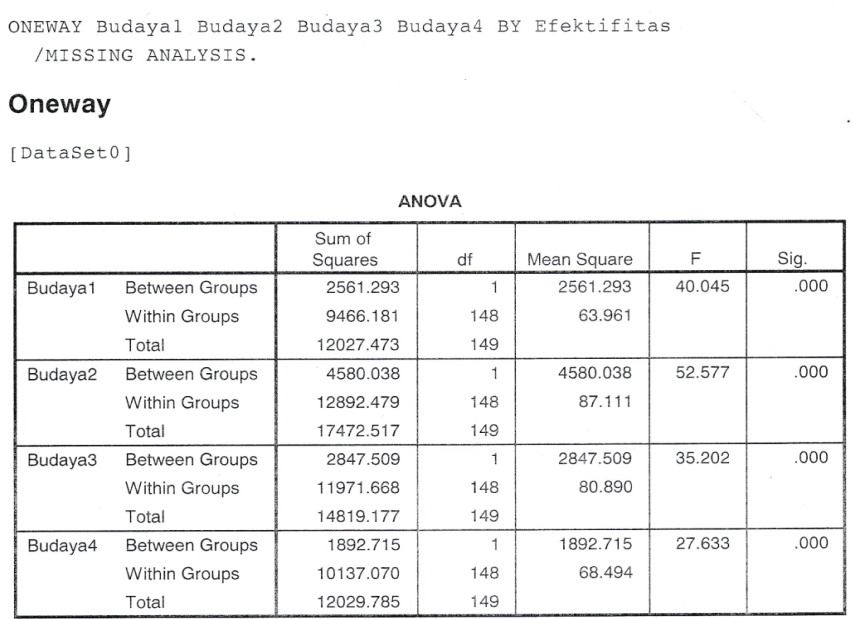

Dari uji ANOVA atau F test, diperoleh F hitung untuk budaya 1 (Tipe budaya Clan) sebesar 40.045 dengan tingkat signifikasi $0,000, \mathrm{~F}$ hitung untuk budaya 2 (Tipe budaya Adhocracy) sebesar 52.577 dengan tingkat signifikasi 0,000, F hitung untuk budaya 3 (Tipe budaya Hierarchy) sebesar 35.202 dengan tingkat signifikasi 0,000, dan F hitung untuk budaya 4 (Tipe budaya Market) sebesar 27.633 dengan tingkat signifikasi 0,000. Keempat nilai signifikansi tersebut lebih kecil dibanding LOS 0,05, sehingga koefisien F menjadi signifikan. Hal ini berarti terdapat perbedaan efektivitas pada keempat tipe budaya tersebut. Hasil ini juga mengindikasikan adanya pengaruh tipe budaya pada tingkat efektivitas institusi (perguruan tinggi). 
Tabel 13. Hasil ANOVA

Uji beda kekuatan budaya - efektivitas

ONEWAY Kekuatan BY Efektifitas

/MISSING ANALYSIS.

\section{Oneway}

[ DataSet0]

ANOVA

Kekuatan

\begin{tabular}{|l|r|r|r|r|r|}
\hline & \multicolumn{1}{|c|}{$\begin{array}{l}\text { Sum of } \\
\text { Squares }\end{array}$} & df & Mean Square & F & Sig. \\
\hline Between Groups & 8.254 & 1 & 8.254 & 37.197 & .000 \\
Within Groups & 32.840 & 148 & .222 & & \\
Total & 41.093 & 149 & & & \\
\hline
\end{tabular}

Dari uji ANOVA atau F test, diperoleh F hitung untuk kekuatan budaya sebesar 37.197 dengan tingkat signifikasi 0,000. Nilai signifikansi tersebut lebih kecil dibanding LOS 0,05, sehingga koefisien F menjadi signifikan. Hal ini berarti terdapat perbedaan efektivitas antara Budaya yang kuat dan lemah. Hasil ini juga mengindikasikan adanya pengaruh kekuatan budaya pada tingkat efektivitas institusi (perguruan tinggi).

Tabel 14. Hasil ANOVA

Uji beda kesesuaian budaya - efektivitas

ONEWAY Kongruen BY Efektifitas

/MISSING ANALYSIS.

\section{Oneway}

[Dataset0]

ANOVA

Kongruen

\begin{tabular}{|l|r|r|r|r|r|}
\hline & \multicolumn{1}{|c|}{$\begin{array}{l}\text { Sum of } \\
\text { Squares }\end{array}$} & \multicolumn{1}{c|}{ df } & Mean Square & $F$ & Sig. \\
\hline Between Groups & .164 & 1 & .164 & .620 & .432 \\
Within Groups & 39.196 & 148 & .265 & & \\
Total & 39.360 & 149 & & & \\
\hline
\end{tabular}


Dari uji ANOVA atau F test, diperoleh F hitung untuk kesesuaian budaya sebesar 0,620 dengan tingkat signifikasi 0,432 . Nilai signifikansi tersebut lebih besar dibanding LOS 0,05, sehingga koefisien F menjadi tidak signifikan. Hal ini berarti terdapat tidak ada perbedaan efektivitas antara Budaya yang kongruen (sesuai) dan tidak kongruen. Hasil ini juga mengindikasikan tidak ada pengaruh kesesuaia budaya pada tingkat efektivitas institusi (perguruan tinggi).

\section{SIMPULAN DAN SARAN}

\section{Simpulan}

Berdasarkan hasil analisis data tentang perbedaan efektivitas ditinjau dari kesesuaian budaya, kekuatan dan tipe budaya tersebut, dapat diambil kesimpulan sebagai berikut:

1. Hasil pembahasan menunjukkan bahwa ketiga variabel budaya memiliki pengaruh yang berbeda-beda terhadap efektivitas. Variabel tipe budaya (terutama tipe budaya Adhocracy) dipandang memiliki pengaruh yang paling tinggi terhadap variabel efektivitas dengan $\mathrm{F}$ hitung sebesar 52.577 dengan tingkat signifikasi 0,000, dibanding dengan variabel kekuatan budaya dengan $\mathrm{F}$ hitung untuk kekuatan budaya adalah 37.197 dengan tingkat signifikasi 0,000, dan variabel kesesuaian budaya memiliki pengaruh yang paling rendah (tidak berpengaruh) terhadap efektivitas dengan $\mathrm{F}$ hitung untuk kesesuaian budaya sebesar 0,620 dengan tingkat signifikasi 0,432.

2. Terkait dengan variabel kesesuaian budaya ditemukan bahwa angka signifikasinya adalah sebesar 0,432 yang lebih besar dibanding LOS 0,05. Hal ini menunjukkan koefisien F menjadi tidak signifikan atau berarti tidak ada perbedaan efektivitas antara Budaya yang kongruen (sesuai) dan tidak kongruen. Hasil tersebut mengindikasikan bahwa variabel kesesuaian budaya tidak memberikan dampak perbedaan tingkat efektivitas institusi (perguruan tinggi), yang berarti bahwa masyarakat Indonesia, khususnya di institusi perguruan tinggi tidak memperhatikan faktor kesesuaian budaya.

3. Tipe budaya yang terbanyak adalah budaya Clan, dengan demikian budaya yang paling sesuai untuk institusi perguruan tinggi di Indonesia adalah budaya Clan .

\section{Saran}

Berdasarkan hasil penelitian, diketahui bahwa tipe budaya yang dimiliki oleh SDM perguruan tinggi lebih dominan dalam mempengaruhi tingginya tingkat efektivitas organisasi, khususnya tipe budaya Adhocracy. Namun, tipe budaya yang terbanyak dipilih adalah budaya Clan. Hal ini memperkuat kesimpulan bahwa masyarakat Indonesia (terutama SDM perguruan tinggi) kurang mempertimbangkan kesesuaian budaya. Oleh karena itu untuk menjaga agar organisasi memiliki efektivitas yang tinggi maka perusahaan harus memperhatikan variabel yang memiliki dampak signifikan seperti kekuatan dan tipe budaya. 


\section{REFERENSI}

An, J. Y., Yom, Y. H., \& Ruggiero, J. S. 2011. Organizational Culture, Quality of Work Life, and Organizational Effectiveness in Korean university hospitals. Journal of Transcultural Nursing, 22(1), 22-30. http://dx.doi.org/10.1177/1043659609360849.

Anderson, J. A. 2000. Explanatory roles of mission and culture: Organizational effectiveness in Tennessee's community colleges. Unpublished PhD thesis. University of Mephis.

Antia, J. M., \& Cuthbert, R. E. 1976. Critical Success Factors in Polytechnic Performance. Educational Management Administration \& Leadership, 5 (14), 14-36.

Ashraf, Giti dan Abd. Kadir, Suhaida bt. 2012. A Review on the Models of Organizational Effectiveness: A Look at Cameron's Model in Higher Education. International Education Studies, Vol. 5, No. 2.

Bluedorn, AC. 1980. Cutting the Gordian Knot: A Critique of the Effectiveness Tradition in Organizational Research. Sociology and Social Research, 64, 477-496.

Cameron, K. 1978. Measuring Organizational Effectiveness in Institutions of Higher Education. Administrative Science Quarterly, 23, 604-632. http://dx.doi.org $/ 10.2307 / 2392582$

1981. Domains of Organizational Effectiveness in Colleges and Universities. Academy of Management Journal, 24 (1), 25-47. http://dx.doi.org/10.2307/255822

1980. Critical Question In Assesing Organizational Effectiveness. Organizational Dynamic, Autumn, 66-80.

1986. A study of organizational effectiveness and its predictors. Management Science, 32(1), 87-112. http://dx.doi.org/10.1287/mnsc.32.1.87.

, Freeman, Sarah J. 1991. Cultural Congruence, Strength, and Type: Relationships to effectiveness. JAI Press Inc, Vol 5, pages 23-38.

Campbell, J.P. 1977. On the Nature of Organizational Effectiveness. In: P.S. Goodman \& J.M. Pennings (Eds.). New Perspectives on Organizational Effectiveness, 36-41. San Francisco: Jossey-Bass.

Clark, B. 1972. The Organizational Saga in High Education. Administrative Science Quarterly, 17: 178-183.

Depdiknas. 2010. Rencana Strategis Departemen Pendidikan Nasional Tahun 2005- 2009. Tersedia pada: http://www. ktsp.diknas.co.id/ktsp sd/ppt3.

Federman, M. 2006. Essay: Towards an effective theory of organizational effectiveness. [Online] Available: http://whatisthemessage.blogspot.com/2006_03_01_ archive.html

Ferdinand, Augusty. 2011. Metodologi Penelitian Manajemen. BP UNDIP. 
Gigliotti, L. 1987. An Adaptation of Cameron's Model of Organizational Effectiveness at the Academic Department Level in Two-year Community Colleges. Unpublished PhD theses. Syracuse University.

Hatch, MJ. 1993. The Dinamic of Organizational Culture. Academy of Management Review, Vol 18, No. 4, p.657-693.

Henry, E. A. 2011. Is the Influence of Organizational Culture on Organizational Effectiveness Universal? An Examination of the Relationship in the Electronic Media (Radio) Service Sector in the English Speaking Caribbean. Unpublished PhD theses. University of Mississippi.

Henry, Jean-François. 2011. Performance Measurement and Organizational Effectiveness: Bridging the Gap. Unpublished PhD thesis. at HEC Montréal.

Hertelendy, A. J. 2010. A Survey of Emergency Medical Services Programs: National EMS Education Program Accreditation and Organizational Effectiveness. Unpublished PhD theses. University of Mississippi Medical Center.

Kaplan, RS. 1983. Measuring Manufacturing Performance: a New Challenge for Managerial Accounting Research. The Accounting Review LVIII(4): 686705 .

1990. Measures for manufacturing excellence. Harvard Business School Press. 
